\title{
Sexual Function, Sexual Activity and Quality of Life in Women with Ovarian and Endometrial Cancer
}

\author{
Sexuelle Funktion, sexuelle Aktivität und Lebensqualität \\ bei Frauen mit Ovarial- und Endometriumkarzinom
}

Authors

Affiliations
P. Harter ${ }^{1}$, I. Schrof ${ }^{1}$, L. M. Karl' ${ }^{2}$, R. Hils ${ }^{3}$, V. Kullmann ${ }^{3}$, A. Traut ${ }^{1,3}$, H. Scheller ${ }^{2}$, A. du Bois ${ }^{1,3}$

${ }^{1}$ Gynecology \& Gynecologic Oncology, Kliniken Essen-Mitte, Essen

2 Prosthodontics, Johannes-Gutenberg University, Mainz

${ }^{3}$ Gynecology \& Gynecologic Oncology, HSK, Wiesbaden

\section{Key words \\ - ovarian cancer \\ - endometrial cancer \\ - dyspareunia \\ Schlüsselwörter \\ - Ovarmalignom \\ - Endometriumkarzinom \\ - Dyspareunie}

$\begin{array}{ll}\text { received } & 11.3 .2013 \\ \text { revised } & 21.3 .2013 \\ \text { accepted } & 14.4 .2013\end{array}$

Bibliography

DOI http://dx.doi.org/

10.1055/s-0032-1328602

Geburtsh Frauenheilk 2013; 73 :

428-432 @ Georg Thieme

Verlag KG Stuttgart · New York . ISSN 0016-5751

\section{Correspondence \\ Dr. Philipp Harter \\ Kliniken Essen-Mitte \\ Gynecology \& \\ Gynecologic Oncology \\ Henricistraße 92 \\ 45136 Essen \\ p.harter@gmx.de}

\section{Abstract \\ V}

Background: Gynecological cancer (GC) is assumed to have an impact on sexual function and activity, but pertinent evidence is currently limited.

Patients and Methods: Sexual function and activity were investigated in patients with gynecological cancer (GC) and in a control group (C), using the "Sexual Activity Questionnaire" (SAQ), the "Female Sexual Function Index" (FSFI), and parts of the EORTC QLQ-C30.

Results: 727 women (335 GC and 392 C) were given a questionnaire and $22.8 \%$ of them responded. Response rates were equivalent for both groups (23.6\% [GC] and 22.2\% [C]). 51.5\% (C) and $59.5 \%$ (GC) were not sexually active, mainly owing to lack of a partner (37\%) or lack of interest (21\%) (C group), and lack of interest (40\%, $\mathrm{p}<0.05)$, physical problems $(31.9 \%, \mathrm{p}<0.05)$, and physical problems suffered by their partner (21\%, $\mathrm{p}<0.05$ ) (GC group). There were significant differences between both groups in the SAQ discomfort score $(p<0.05)$, but no significant differences in quality of life or other scores for sexuality.

Conclusion: The quality of sexuality tends to be impaired in GC patients, but this does not appear to influence quality of life. A shift in priorities caused by the considerable anxiety about surviving the cancer might explain our findings.

\section{Introduction \\ $\nabla$}

Gynecological malignancies are a leading cause of morbidity in women in the United States and the European Union [1,2]. According to the most current cancer statistics, the standardized incidence rate for combined malignant ovarian and endo-

\section{Zusammenfassung}

$\nabla$

Hintergrund: Es wird angenommen, dass gynäkologische Malignome einen Einfluss auf die sexuelle Funktion haben, aber die diesbezügliche Evidenz ist begrenzt.

Methoden: Sexuelle Funktion und Aktivität wurden unter Verwendung des „Sexual Activity Questionnaire“ (SAQ), des „Female Sexual Function Index“ (FSFI) und von Teilen des EORTC QLQ 30 an Patientinnen mit gynäkologischen Tumoren (GC) und einer Kontrollgruppe von Nichttumorpatientinnen (C) untersucht.

Ergebnisse: 727 Frauen (335 GC, 392 C) erhielten einen Fragebogen, von denen 22,8\% antworteten; die Rücklaufquote war in beiden Gruppen identisch (GC 23,6\%, C 22,2\%). 51,5\% (C) bzw. 59,5\% (GC) waren nicht sexuell aktiv, hauptsächlich aufgrund des Fehlens eines Partners (37\%) oder Desinteresse (21\%) in der Kontrollgruppe sowie Desinteresse $(40 \%, \mathrm{p}<0,05)$, physischen Problemen $(31,9 \%, p<0,05)$ und physischen Störungen beim Partner $(21 \%, \mathrm{p}<0,05)$ bei den Tumorpatientinnen. Zudem war der SAQ-Score in beiden Gruppen signifikant unterschiedlich, nicht aber die Lebensqualität und andere sexuelle Parameter.

Schlussfolgerung: Die Qualität der Sexualität ist bei Patientinnen mit GC tendenziell beeinträchtigt, was aber keinen Einfluss auf deren Lebensqualität zu haben scheint. Unsere Beobachtungen könnten durch eine Verlagerung der Prioritäten unter dem Eindruck der lebensbedrohlichen Erkrankung zu erklären sein.

metrial tumors was $\sim 34 / 100000$ in Europe and $\sim 24 / 100000$ worldwide, with the US figures on a par with the worldwide data $[3,4]$.

With the introduction of effective radical surgery and adjuvant chemotherapy and/or radiotherapy, the survival of patients with gynecological cancer has improved substantially [5-7]. Exact figures 
about the respective percentage of primary diagnoses in cancer survivors are difficult to obtain, but malignancies of the female genitalia appear to be the most common underlying disease in long-term survivors [8].

Longer survival times and potential treatment-related morbidity have led to a greater emphasis being placed on other criteria in addition to survival, such as health-related quality of life (HRQL) including sexuality. Such endpoints are also increasingly used in intervention studies in oncology [9-11]. While certain basic criteria for HRQL are universally applicable, there are a growing number of multidimensional instruments used to measure quality of life. The selection of reliable and validated instruments (such as the EORTC QLQ-C30) is therefore important and caution is mandated when comparing results between studies [12].

All treatment modalities for gynecologic malignancies, i.e., pelvic surgery, radiation and drug therapy, have the potential to impair sexual function through a variety of anatomical, physiological and psychological pathways, and sexual dysfunction is indeed frequently mentioned in the literature [13-19]. However, controlled studies are relatively rare, and their results conflicting. While some report significant and substantial differences between women with cancer and healthy controls [13,14,18,19], others deny such a disparity [20], and the impact of sexual dysfunction on quality of life is a matter of controversy [14,15].

Valid empirical data on the prevalence of sexual dysfunction in patients with gynecological malignancies based on comparisons with age-matched cancer-free controls is relatively rare; a higher prevalence, if present, may be an expression of the underlying disease itself, the patient's success in coping or other important confounding factors rather than the treatment itself $[21,22]$. According to the literature, the significance of manifest sexual dysfunction in survivors of a life-threatening disease may be very different from that in a healthy population [23].

Evidence-based decisions on the relevance of sexual dysfunction in gynecological cancer survivors are currently not possible, and hence no recommendations can be made with regard to possible remedies. Not only is the evidence for a higher incidence of impaired sexual desire, functioning and pleasure and relevance of this for the quality of life of women with gynecological cancer relatively weak and controversial, but it is also unclear if and to which extent the dysfunction is attributable to the treatment, the disease itself or to psychological aspects of the patient's coping strategy [20]. We therefore conducted a cross-sectional study to investigate sexual functioning in patients with ovarian and endometrial cancer and compared the results with those of healthy controls.

\section{Methods}

$\nabla$

This study was approved by the ethics committee of the Medical Association of the German Federal State of Hesse. Since 2001, all consecutive patients with gynecologic cancer treated at our hospital are prospectively recorded in a clinical tumor registry. All patients' records are updated annually.

In order to be eligible for the study, patients had to fulfill the following criteria: malignancy of the ovary or endometrium, and primary therapy at our institution completed $\geq 12$ months before enrolment without any evidence of relapse. A total of 335 patients who met these criteria were identified and a control sample without oncological disease consisting of 392 age-matched women was recruited in the Department of Prosthodontics, Uni- versity Hospital Mainz. The questionnaire was sent out by mail between December 2009 and May 2010.

When designing the questionnaire, we attempted to strike a balance between a thorough and comprehensive assessment and a level of complexity which would not deter compliance; in view of this consideration, the decision was taken not to do a full HRQL evaluation. The questionnaire comprised three pages of validated German versions of the following items:

1. The "Sexual Activity Questionnaire" (SAQ): The SAQ comprises three sections covering sexual activity, perception of desire and possible complaints during sexual intercourse. The first section contains questions on the presence of a partner, change(s) of partner(s) in the past 6 months and current sexual activity. Depending on the answer to the latter question, respondents are requested to either answer questions on sexual function and experience or on the reasons for sexual inactivity. 2. An excerpt of the "Female Sexual Function Index" (FSFI-d) on frequency, difficulties and satisfaction with attained orgasms is assessed using a 5-point verbal rating scale.

3. An excerpt of the European Organisation for the Research and Treatment of Cancer Quality of Life Questionnaire Core 30 (EORTC QLQ-C30) which investigates patient self-assessment of general health and quality of life (both of which are not sufficiently covered in 1 . and 2.) on a numerical rating scale from 1 ("very bad") to 7 ("excellent").

All questionnaires are validated in terms of their psychometric properties (using Cronbach's $\alpha$-values of $\geq 0.8[24,25]$ ) and are used extensively in pertinent investigations [16,17,26-30].

Three scores were calculated based on the SAQ: a pleasure score (sum of points for questions 1, 2, 4, 7, 8 and 10 in section 3; more points equal more pleasure), a discomfort score (sum of points for questions 5 ["perceived dryness during intercourse during the past 4 weeks"] and 6 ["pain or other complaints during intercourse during the past 4 weeks"]; more points equal more discomfort) and a habit score (points for question 9 [comparison of the frequency during the past 4 weeks with usual habits]; more points equal a higher frequency); an orgasm score was calculated as the sum of points in the three FSFI-d questions (more points equal more frequent and/or more satisfactory orgasms). The point score for health and quality of life was calculated based on the EORTC manual [31].

All statistical analyses were done with SPSS 16.0 (Chicago, IL, USA). Patients with incomplete datasets were only excluded in the analyses where variables were missing but were included in all other evaluations. Comparisons of two or more groups of discrete variables were done with Fisher's exact test or $X^{2}$ test. Median, mean, standard deviation and $95 \%$ confidence interval were calculated for metric variables, and group differences were evaluated with the Mann-Whitney U test. All p-values were twosided, and $\mathrm{p}<0.05$ was considered significant.

\section{Results \\ $\nabla$}

Seventy-nine patients (23.6\%) and 87 control subjects (22.2\%) returned a completed questionnaire and were eligible for evaluation. Forty-nine patients $(62.0 \%)$ had undergone treatment for ovarian cancer and 30 patients (38.0\%) for endometrial cancer. Forty-four patients (55.7\%) received adjuvant or primary chemotherapy and 19 patients (24.1\%) were treated with radiotherapy. The median interval after the first diagnosis was 4.1 years (range: 
Table 1 Baseline data, relationship status and sexual activity in patients and controls.

\begin{tabular}{|c|c|c|c|c|}
\hline \multirow[t]{2}{*}{ Variables } & & \multicolumn{3}{|c|}{ n (\% of valid answers) } \\
\hline & & Controls & Patients & p-value (2-sided) \\
\hline$n$ & & 87 & 79 & \\
\hline \multirow[t]{2}{*}{ Age } & mean, years & 57 & 62 & 0.237 \\
\hline & range, years & $36-80$ & $18-86$ & \\
\hline \multirow[t]{3}{*}{ Age groups (menopausal status) } & $\leq 49 \mathrm{yrs}$ & $19(25.3)$ & $14(17.7)$ & 0.326 \\
\hline & $\geq 50 \mathrm{yrs}$ & $56(74.7)$ & $65(82.3)$ & \\
\hline & $\mathrm{n} / \mathrm{a}$ & 12 & - & \\
\hline \multicolumn{5}{|l|}{ SAQ, 1st section } \\
\hline \multirow[t]{3}{*}{ Steady relationship } & yes & $59(74.7)$ & $58(80.6)$ & 0.765 \\
\hline & no & $19(25.3)$ & $14(19.4)$ & \\
\hline & $\mathrm{n} / \mathrm{a}$ & 8 & 7 & \\
\hline \multirow{3}{*}{$\begin{array}{l}\text { Change of sexual partner } \\
\text { during the past } 6 \text { months }\end{array}$} & yes & $3(4.0)$ & - & 0.239 \\
\hline & no & $72(96.0)$ & $69(100.0)$ & \\
\hline & $\mathrm{n} / \mathrm{a}$ & 12 & 10 & \\
\hline \multirow[t]{2}{*}{ Sexual activity } & yes & $43(49.4)$ & $32(40.5)$ & 0.277 \\
\hline & no & $44(50.6)$ & $47(59.5)$ & \\
\hline
\end{tabular}

Table 2 Reasons for sexual inactivity cited by eligible subjects (multiple answers permitted).

\begin{tabular}{|c|c|c|c|}
\hline \multirow{2}{*}{$\begin{array}{l}\text { Reasons for } \\
\text { sexual inactivity }\end{array}$} & \multicolumn{3}{|c|}{ n (\% of valid answers) } \\
\hline & $\begin{array}{l}\text { Controls } \\
(n=44)\end{array}$ & $\begin{array}{l}\text { Patients } \\
(n=47)\end{array}$ & $\begin{array}{l}\text { p-value } \\
\text { (2-sided) }\end{array}$ \\
\hline \multicolumn{4}{|l|}{ SAQ, 2nd section } \\
\hline No partner & $17(38.6)$ & $11(23.4)$ & 0.172 \\
\hline $\begin{array}{l}\text { General well-being (fatigue), } \\
\text { patient }\end{array}$ & $4(9.1)$ & $3(6.4)$ & 0.708 \\
\hline $\begin{array}{l}\text { General well-being (fatigue), } \\
\text { partner }\end{array}$ & $4(9.1)$ & $2(4.3)$ & 0.425 \\
\hline No interest in sex, patient & $9(20.5)$ & $19(40.4)$ & 0.044 \\
\hline No interest in sex, partner & $4(9.1)$ & $7(14.9)$ & 0.525 \\
\hline Physical problem, patient & $4(9.1)$ & $13(27.7)$ & 0.031 \\
\hline Physical problem, partner & $2(4.5)$ & $10(21.3)$ & 0.028 \\
\hline Other reasons & $19(43.2)$ & $8(17.0)$ & 0.011 \\
\hline
\end{tabular}

1.3-10.3). The mean age of the 79 patients who completed the questionnaire was 62 years (range: 18-86 years). Control subjects were on average 5 years younger (mean: 57 years; range: 36-80 years), but age and menopausal status did not differ significantly between groups. Most subjects in both groups $(74.7 \%$ of controls and $80.6 \%$ of patients) lived together with a partner. Changes of sexual partners in the 6 months preceding the questionnaire were rare ( $4.0 \%$ of controls, none of the patients). Fortythree control subjects (49.5\%) and 32 patients (40.5\%) described themselves as "currently sexually active" ( Table 1 ). This difference was not significant.

The lack of a sexual partner was the single most important reason for sexual inactivity in the control group (given by 17 subjects [38.6\%] who described themselves as sexually inactive). In contrast, patients most frequently cited lack of interest as the reason for sexual inactivity $(n=19,40.4 \%)$. The lack of sexual interest was significantly higher in GC patients $(\mathrm{p}<0.05)$ as were physical problems experienced by the patient herself (31.9 vs. $20.5 \%$, $\mathrm{p}<0.05$ ) or her partner ( 44.7 vs. $4.5 \%, \mathrm{p}<0.05$ ); “other" reasons were cited more frequently by controls ( 43.2 vs. $17.0 \%, \mathrm{p}<0.05$ ) ( Table 2).
The only point score with a significant difference between groups was the discomfort score with $2.62 \pm 2.3$ (95\% CI: 2.2-3.0) points in patients vs. $1.34 \pm 1.7(95 \% \mathrm{Cl}: 1.1-1.3)$ points in controls $(\mathrm{p}<0.05)$. There was a nonsignificant tendency towards reduced pleasure ( $9.4 \pm 4.3$ vs. $10.7 \pm 3.8$ points, $\mathrm{p}=0.139)$ and lower orgasm scores $(10.7 \pm 3.6$ vs. $12.0 \pm 3.0$ points, $\mathrm{p}=0.094)$ in patients compared with controls. Self-rated health status and quality of life showed no appreciable difference between groups with 67 (C) versus 69 (GC) out of 100 possible points ( Fig. 1 ).

\section{Discussion}

The results of the present study confirm a high incidence of sexual inactivity and discomfort during sexual intercourse in gynecological cancer survivors. In accordance with the mental and physical aspects of cancer survivorship and treatment sequelae, patients reported a lack of interest and physical problems as the most frequent reasons for sexual inactivity (59.5\%), and the SAQ discomfort score for GC women was significantly higher than in control subjects. However, a comparison between groups of other aspects of sexual function (pleasure, habit, and orgasm score) and of quality-of-life indicators did not yield an appreciable difference. Due to the lack of a thorough evaluation of possible confounding variables, this does not directly rule out the impact of doubtlessly increased - discomfort during sexual intercourse on quality of life. However, the patients' general well-being was on a par with that of the control subjects, and it is unlikely - albeit not impossible - that this is due to compensating factors outside the scope of this investigation. Therefore, the impact of sexual impairment on quality of life in our patient sample appears to be limited.

However, certain methodological aspects of the study mean that these results should be interpreted with caution. First of all, the response rates were rather low, with only around 1 in 4 questionnaires returned in both groups. However, the participation rate in published postal surveys of sexual issues is often only between 15 and 50\% [32-36], and comparison between responders and non-responders published by Dunne et al. [37] showed only marginal differences on re-investigation. In our series, we did not analyze the non-responders. Some patients responded with a num- 


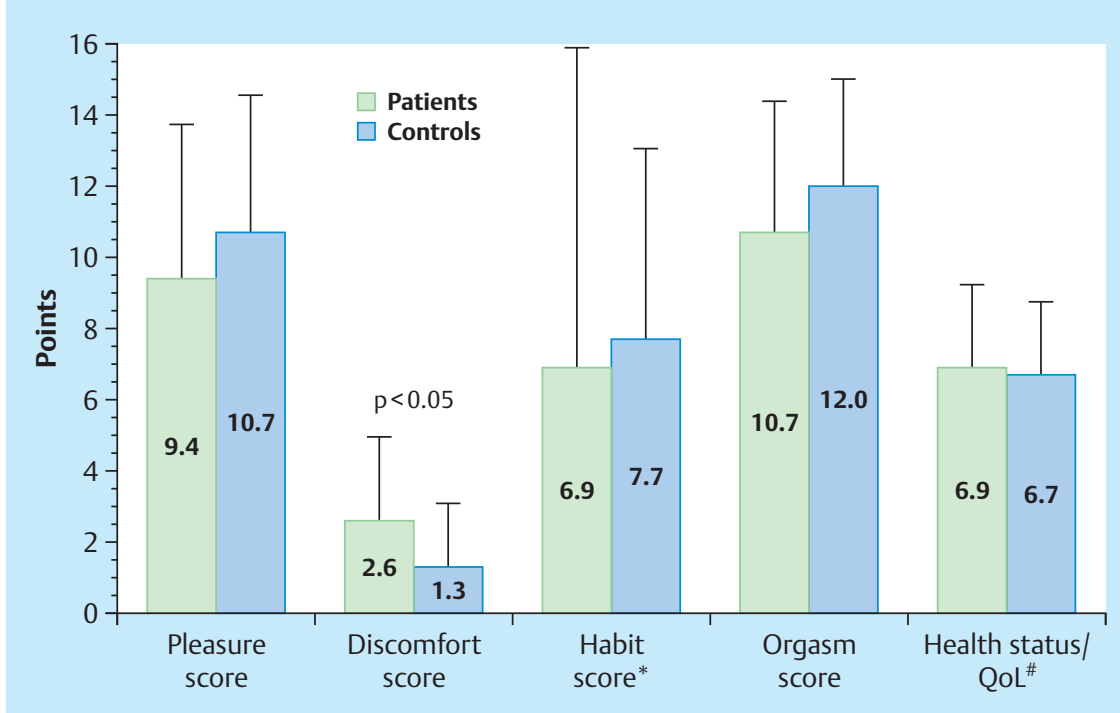

Fig. 1 Self-assessment results in patients and controls (Pleasure Score, Discomfort Score and Habit Score from SAQ, Orgasm Score from FSFI, Health Status and QoL from EORTC QLQ-C30; * multiplied by 10 ; ${ }^{*}$ divided by ten for better clarity).

ber of major concerns regarding such a questionnaire so that we abandoned our intention of reminding non-responding patients. The fact that rates in both groups of the present study were approximately equivalent also rather contradicts systematic bias. Of course, the limited number of participating patients and controls is in itself a limiting factor with regard to the general applicability of our results. The same applies to the chosen entities "ovarian cancer" and "endometrial cancer". Our results cannot be generalized for other gynecologic cancers such as vulvar or cervical cancer. There could be significant differences due to the different surgical procedures and types of adjuvant treatment involved, which could include higher rates of radiotherapy compared to the investigated cohorts. Unfortunately, our sample size is too small to perform a meaningful subgroup analysis with regard to age, time elapsed since therapy, type of surgery, type of adjuvant therapy, etc.

Even though the data was obtained from participants in a prospective study, the results are based on a single cross-sectional questionnaire, and thus it is impossible to determine changes in sexual function over time in either group. Moreover, the decision to keep the questionnaire short inherently limited the scope of the results, especially with regard to quality of life and its possible connection to sexual function.

Other methodological aspects strengthen the study's results and provide information beyond the scope of most existing cross-sectional studies; they include the case-control study design, the meticulous documentation of all relevant clinical data and, in particular, the control group with its excellent age match and probable absence of any of the physical and mental difficulties implicated in sexual dysfunction in gynecological cancer survivors. The difference in sexual activity between patients and controls in the present study - 40 vs. $50 \%$ - was lower than expected. However, sexual activity in the general female population of the same age bracket is not necessarily much higher. In a study published by Lindau et al., the self-reported rate of sexual activity declined from $73 \%$ in subjects aged between 57 and 64 years to $53 \%$ for women between the age of 65 and 74 years, and to $26 \%$ for women between 75 and 85 years of age. Other results of the study in 3005 adults (1550 females) were also remarkably similar to our findings: half of the women who were sexually active reported at least one troublesome sexual problem, and the most common reason cited for lack of activity was low desire (reported in $43 \%$ ), a figure almost precisely similar to the finding in our study [38].

While an appreciable, albeit moderate, impairment of sexual function and - especially - of desire in gynecological cancer survivors is clear in the present sample, its biological and psychological background is much less straightforward. First of all, the physical problems of the patients' partners are significantly more common than reported for the partners of controls, indicating the complex nature of possible causes; the complete absence of repercussions on quality of life and self-rated health status indicate a similar complexity of consequences. However, we have to be cautious about generalizing our results on quality of life because only 2 questions from the quality-of-life questionnaire were studied and some effects may have been overlooked due to this limited approach.

Our study raises some doubt about the equation of "sexual functioning" with "quality of life" in female cancer survivors sometimes found, implicitly or explicitly, in the literature [39]. In the present study, women who had survived ovarian or endometrial cancer generally assessed their own health status and quality of life as satisfactory (approximately in the middle between "very bad" and "excellent") according to the well-validated EORTC QLQ-C30 assessment, notwithstanding certain physical impairments in sexual activity. This is in accordance with other published studies $[13,20,23]$ and possibly indicates a significant shift in priorities experienced by cancer survivors. In keeping with our personal experience, the first and foremost concern of survivors of ovarian and endometrial cancer is tumor recurrence [28]; according to the present study, this would seem to put other difficulties in life - including a possible impairment of sexual desire and fulfillment - into perspective [23]. It is difficult to draw definitive conclusions from our findings which can be used for patient counseling. The following conclusion could serve as a summary of our clinical experience and of the limited results of our study. The problem of sexual function might be overestimated by us in some patients but could be a major factor influencing quality of life in others. Patients and their partners need all the support we can offer. 


\section{Conflict of Interest}

$\nabla$

The study was funded by "Let's GO", an independent association which supports women with gynecologic cancer affiliated to the Dr. Horst Schmidt Klinik, Wiesbaden, Germany (http://www. lets-go-ev.org/startseite/). "Let's GO" was not involved in any aspects of the study apart from the grant.

All authors declare they have no relevant conflicts of interest.

\section{References}

1 Sant M, Allemani C, Santaquilani $M$ et al. EUROCARE-4. Survival of cancer patients diagnosed in 1995-1999. Results and commentary. Eur J Cancer 2009; 45: 931-991

2 Jemal A, Siegel $R$, Ward E et al. Cancer statistics, 2009. CA Cancer J Clin 2009; 59: 225-249

3 Howlader N, Noone AM, Krapcho $M$ et al. SEER cancer statistics review, 1975-2008, based on November 2010 SEER data submission

4 Husmann G, Kaatsch P, Katalinic A et al. Krebs in Deutschland 2005/ 2006 - Häufigkeiten und Trends. Beiträge zur Gesundheitsberichterstattung des Bundes. ISBN: 978-3-89606207-9

5 Harter P, Muallem ZM, Buhrmann C et al. Impact of a structured quality management program on surgical outcome in primary advanced ovarian cancer. Gynecol Oncol 2011; 121: 615-619

6 Creasman WT, Odicino F, Maisonneuve P et al. Carcinoma of the corpus uteri. FIGO 26th annual report on the results of treatment in gynecological cancer. Int J Gynaecol Obstet 2006; 95 (Suppl. 1): S105-S143

7 Heintz AP, Odicino F, Maisonneuve P et al. Carcinoma of the ovary. FIGO 26th annual report on the results of treatment in gynecological cancer. Int J Gynaecol Obstet 2006; 95 (Suppl. 1): S161-S192

8 Hewitt M, Breen N, Devesa S. Cancer prevalence and survivorship issues: analyses of the 1992 National Health Interview Survey. J Natl Cancer Inst 1999; 91: 1480-1486

9 du Bois A, Lück HJ, Meier Wet al. A randomized clinical trial of cisplatin/ paclitaxel versus carboplatin/paclitaxel as first-line treatment of ovarian cancer. J Natl Cancer Inst 2003; 95: 1320-1329

10 Greimel ER, Bjelic-Radisic V, Pfisterer J et al. Randomized study of the Arbeitsgemeinschaft Gynaekologische Onkologie Ovarian Cancer Study Group comparing quality of life in patients with ovarian cancer treated with cisplatin/paclitaxel versus carboplatin/paclitaxel. J Clin Oncol 2006; 24: 579-586

11 von Pawel J, Schiller JH, Shepherd FA et al. Topotecan versus cyclophosphamide, doxorubicin, and vincristine for the treatment of recurrent small-cell lung cancer. J Clin Oncol 1999; 17: 658-667

12 Rusthoven JJ. Are quality of life, patient preferences, and costs realistic outcomes for clinical trials? Support Care Cancer 1997; 5: 112-117

13 Aerts L, Enzlin P, Verhaeghe J et al. Sexual and psychological functioning in women after pelvic surgery for gynaecological cancer. Eur J Gynaecol Oncol 2009; 30: 652-656

14 Gershenson DM, Miller AM, Champion VL et al. Reproductive and sexual function after platinum-based chemotherapy in long-term ovarian germ cell tumor survivors: a Gynecologic Oncology Group study. J Clin Oncol 2007; 25: 2792-2797

15 Lindau ST, Gavrilova N, Anderson D. Sexual morbidity in very long term survivors of vaginal and cervical cancer: a comparison to national norms. Gynecol Oncol 2007; 106: 413-418

16 Becker M, Malafy T, Bossart $M$ et al. Quality of life and sexual functioning in endometrial cancer survivors. Gynecol Oncol 2011; 121: 169173

17 Fotopoulou C, Neumann U, Klapp C et al. Long-term effects of neovaginal reconstruction with sigmoid loop technique on sexual function and self image in patients with gynecologic malignancies: results of a prospective study. Gynecol Oncol 2008; 111: 400-406
18 Jensen PT, Groenvold M, Klee MC et al. Longitudinal study of sexual function and vaginal changes after radiotherapy for cervical cancer. Int J Radiat Oncol Biol Phys 2003; 56: 937-949

19 Liavaag AH, Dørum A, Bjøro T et al. A controlled study of sexual activity and functioning in epithelial ovarian cancer survivors. A therapeutic approach. Gynecol Oncol 2008; 108: 348-354

20 Frumovitz M, Sun CC, Schover LR et al. Quality of life and sexual functioning in cervical cancer survivors. J Clin Oncol 2005; 23: 7428-7436

21 Amsterdam A, Carter J, Krychman M. Prevalence of psychiatric illness in women in an oncology sexual health population: a retrospective pilot study. J Sex Med 2006; 3: 292-295

22 Tang CS, Lai BP, Chung TK. Influences of mastery, spousal support, and adaptive coping on sexual drive and satisfaction among chinese gynecologic cancer survivors. Arch Sex Behav 2010; 39: 1191-1200

23 Stewart DE, Wong F, Duff S et al. "What doesn't kill you makes you stronger": an ovarian cancer survivor survey. Gynecol Oncol 2001; 83: 537-542

24 Burri A, Cherkas L, Spector T. Replication of psychometric properties of the FSFI and validation of a modified version (FSFI-LL) assessing lifelong sexual function in an unselected sample of females. J Sex Med 2010; 7: 3929-3939

25 Vistad I, Fosså SD, Kristensen GB et al. The sexual activity questionnaire: pychometric properties and normative data in a norwegian population sample. J Womens Health (Larchmt) 2007; 16: 139-148

26 Hawighorst-Knapstein S, Fusshoeller C, Franz C et al. The impact of treatment for genital cancer on quality of life and body image-results of a prospective longitudinal 10-year study. Gynecol Oncol 2004; 94: 398-403

27 Blumel JE, Chedraui P, Baron G et al. Sexual dysfunction in middle-aged women: a multicenter Latin American study using the Female Sexual Function Index. Menopause 2009; 16: 1139-1148

28 Carter J, Sonoda Y, Baser RE et al. A 2-year prospective study assessing the emotional, sexual, and quality of life concerns of women undergoing radical trachelectomy versus radical hysterectomy for treatment of early-stage cervical cancer. Gynecol Oncol 2010; 119: 358-365

29 Rodrigues AC, Teixeira R, Teixeira $T$ et al. Impact of pelvic radiotherapy on female sexuality. Arch Gynecol Obstet 2012; 285: 505-514

30 Thirlaway K, Fallowfield L, Cuzick J. The Sexual Activity Questionnaire: a measure of women's sexual functioning. Qual Life Res 1996; 5: 81-90

31 EORTC. EORTC QLQ-C30 Scoring Manual. Brussels: 2001

32 Kar N, Koola MM. A pilot survey of sexual functioning and preferences in a sample of English-speaking adults from a small South Indian town. J Sex Med 2007; 4: 1254-1261

33 Lonnée-Hoffmann RA, Schei B, Eriksson NH. Sexual experience of partners after hysterectomy, comparing subtotal with total abdominal hysterectomy. Acta Obstet Gynecol Scand 2006; 85: 1389-1394

34 Stulhofer A, Gregurovic M, Pikic A et al. Sexual problems of urban women in Croatia: prevalence and correlates in a community sample. Croat Med J 2005; 46: 45-51

35 Lang AJ, Rodgers CS, Laffaye C et al. Sexual trauma, posttraumatic stress disorder, and health behavior. Behav Med 2003; 28: 150-158

36 Young $M$, Denny $G$, Young $T$ et al. Sexual satisfaction among married women age 50 and older. Psychol Rep 2000; 86: 1107-1122

37 Dunne MP, Martin NG, Bailey JM et al. Participation bias in a sexuality survey: psychological and behavioural characteristics of responders and non-responders. Int J Epidemiol 1997; 26: 844-854

38 Lindau ST, Schumm LP, Laumann EO et al. A study of sexuality and health among older adults in the United States. N Engl J Med 2007; 357: 762-774

39 Burns M, Costello J, Ryan-Woolley B et al. Assessing the impact of late treatment effects in cervical cancer: an exploratory study of women's sexuality. Eur J Cancer Care (Engl) 2007; 16: 364-372 